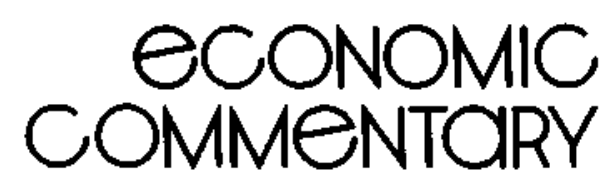

Federal Reserve Bank of Cleveland

\title{
Are the Great Lakes Cities Becoming Service Centers?
}

by Erica L. Groshen and Laura Robertson

D uring the past 20 years, American business has restructured itself along many dimensions. While some industries have suffered a protracted decline, others have expanded, moved to new regions, or revamped their production processes. Two much-noted effects of this restructuring are the elimination of many manufacturing jobs nationwide and sluggish overall employment growth in the large cities bordering the Great Lakes.

On first glance, it is tempting to conclude that these Midwest metropolises, once dominated by factory jobs, shrank because manufacturers moved south or west. To counter this assessment-and its extrapolation into a gloomy forecast -some optimists in the region have pinned their hopes on attracting or developing infant manufacturing industries to revitalize the large factories in the area's urban cores.

This Economic Commentary argues that, in many respects, such conclusions do not fit the facts. On net, and controlling for fasier overall growth outside the region, the manufacturing jobs lost by the Midwest's major cities did not resurface in other areas of the country. Rather, those that did not disappear altogether either became urban service-industry positions or were replaced by nural or \$maljcity factory jobs. Thus, the overall impact of these various trends has been the partial transformation of the 10 largest Great Lakes cities into service centers for their surrounding communities.
These new patterns also suggest a major shift in the economic role of these cities, which since the turn of the century have accounted for a disproportionate share of U.S. factory jobs. Traditionally, sales of locally manufactured products to people outside the metropolitan area have financed purchases of goods and services from elsewhere. Now, these cities rely increasingly on sales of services to out-of-towners to pay for products imported from other regions.

\section{Basic Trends}

The cities covered in this study include the five largest U.S. metropolitan statistical areas (MSAs) bordering the Great Lakes (Chicago, Milwaukee. Cleveland. Detroit, and Buffalo), plus five others that are located in the region and that exhibit many of the same characteristics as the first group (Pittsburgh. Columbus, Cincinnati, Indianapolis. and Minneapolis-St. Paul).

The first column of table 1 shows that between the business cycle peaks of 1969 and 1989, jobs grew more slowly in eight of these cities than in the United States as a whole. Together, employment in alt 10 expanded by only 28.4 percent, compared to 52.0 percent nationwide. Employment in the Great Lakes states only slightly outpaced the region's large-city average. ${ }^{\prime}$

During this time, the industrial mix of jobs in the United States shifted dramatically. The predominant changes were the shrinking of manufacturing's
Since the turn of the century, the Midwest's largest cities have been home to a disproportionate share of U.S. manufacturing jobs. Now, with jobs in this sector dwindling, some have suggested that these erstwhile urban giants have lost their reason for being. In this article, the authors argue that rather than fading away, the region's 10 major metropolises are reemerging as service centers for their surrounding communities, which have picked up many of the factory jobs that have left the cities.

share of employment by a least a third and the expansion of services" share by at least a half. ${ }^{2}$ Employment shifts among the other major industrial groups paled by comparison.

Most of this changeover can be traced to U.S, manufacturers' tremendous success in boosting productivity. New technologies embodied in sophisticated capital equipment, just-in-time production techniques, and outsourcing of services led to a 2.9 percent drop in manufacturing jobs over the 1969-89 period. This diminishing need for factory workers contrasted sharply with the rapid growth in nonmanufacturing jobs, particularly in the service industries. Many firms found it was more cost effective to contract out for functions they had previously performed inhouse, such as data processing, machine maintenance, and legal work. 
New jobs were also created to meet the growing demand for day care and health and personal services, reflecting demographic trends, medical advances, and an increasing number of single-parent and two-earner families. Since service productivity picked up only slowly over the period, this rising demand translated largely into new jobs.

Table 1 shows that over the last two decades, manufacturing jobs in the principal Great Lakes cities shrank 27.4 percent, while service employment skyrocketed 108.4 percent. Furthermore. overall growth was slower in the cities and region than in the nation as a whole. Manufacturing posted a loss in nine cities (the single exception is Minneapolis), while services added signiftcantly more jobs than any other industry in all 10 locales.

\section{- Is "Too Much" Manufacturing to Blame?}

Knowing that the largest components of employment shifts in the United States during these years were the drop-off in manufacturing jobs and the increase in service slots, some people have inferred that the Midwest metropolises were held back by their manufacturing focus as wel] as by their low initial concentration of jobs in the burgeoning service industries. All 10 cities started with above-average concentrations of factory jobs, while only four had higher-than-normal concentrations of service positions.

In fact, job-market fluctuations experienced in the Great Lakes cities between 1969 and 1989 did not simply mirror national shifts in the distribution of industrial employment: The losses and gains exhibit too much diversity and too little overall growth. This is apparent from figure 1 , which shows each city's overall employment growth relative to the nation, along with the effect exerted on that growth by the city's initial industrial mix. ${ }^{3}$ For example, Minneapolis and Columbus added jobs at rates 17 and $t 2$ percentage points faster than the U.S. rate, respectively, while Pittsburgh and Cleveland lagged the national pace by more than 42 percentage points. These differences in citywide em-

TABLE 1 EMPLOYMENT GROWTH, 1969-89

(Percent change)

\begin{tabular}{lcccc} 
& Total & Manufacturing & Services & All Other \\
\cline { 2 - 5 } Minneapolis & 69.1 & 17.4 & 158.7 & 62.1 \\
Columbus & 64.5 & -11.6 & 157.7 & 68.0 \\
Indianapolis & 47.7 & -20.1 & 144.8 & 52.3 \\
Cincinnati & 42.8 & -16.0 & 112.5 & 50.3 \\
Milwaukee & 34.5 & -17.4 & 124.2 & 37.8 \\
Chicago & 21.8 & -35.4 & 99.6 & 26.4 \\
Detroit & 19.8 & -27.5 & 103.1 & 24.1 \\
Buffalo & 12.0 & -43.0 & 100.1 & 14.8 \\
Pittsburgh & 9.8 & -50.8 & 77.9 & 13.2 \\
Cleveland & 9.6 & -34.2 & 79.3 & 13.0 \\
\hline Great Lakes cities & 28.4 & -27.4 & 108.4 & 32.3 \\
Great Lakes states & 31.0 & -17.0 & 109.5 & 33.8 \\
U.S. average & 52.0 & -2.9 & 125.3 & 50.7 \\
\hline
\end{tabular}

SOURCE: U.S. Department of Commetce, Bureau of Economic Analysis, Regional Economic Information Service Data Base.

ployment growth far exceed what can be explained by local variations in the 1969 mix of industries. In particular. the magnitude of employment changes in both manufacturing and services deviated substantially from the U.S. average in each locale (see columns two and three of table 1).

In three instances, the industrial mix pushed the employment growth rate in the opposite direction of the city's actual growth rate. Moreover, even when the mix effect was pointing in the right direction, it accounted for only a small portion of the difference in growth.

Employment changes in the Midwest reflect strong influences that are independent of those driving the U.S. aggregate. More important than initial variations in industry shares of employment, the Great Lakes cities had different growth rates within their broad industries. Thus, the next step is to examine the strong geographic element of industrial restructuring masked in the national aggregates. To do that. we focus on the regional concentration of employment in services and manufacturing, the two targest and most rapidly changing segments of total employment. ${ }^{4}$
Where Did the Midwest's Manufacturing Jobs Go?

Since a large part of the weaker-thanexpected overall employment growth in the Midwest cities is attributable to their disproportionate loss of factory jobs, should we infer that the whole region has relinquished its comparative advantage as a manufacturing center? If not, where did these jobs go?

To answer this question, we use a measure of the Midwest's concentration in particular industries. This metric, called the location quotient (LQ), is a city's or region's employment share for a given industry divided by the U.S. share. In effect, it isolates local sectoral job trends independent of national trends. LQs below one mean that the area has a lower-than-average concentration in the industry. Ratios above one reflect some local specialization.

As shown in figure 2, the LQs for manufacturing jobs decreased in nine of the 10 cities examined here between 1969 and 1989. In simple terms, this means that factory jobs declined more in these locales than in the nation as a whole. even after controlling for the Midwest's shrinking population share. In 1969. all 10 cities specialized in manufacturing. Twenty years later, three (Columbus, Indianapolis, and Pittsburgh) had lost that specialization and 
FIGURE 1 CONTRIBUTION OF INDUSTRY MIX EFFECT TO DIFFERENCES IN CITY-U.S. JOB GROWTH, 1969-89

Percentage points

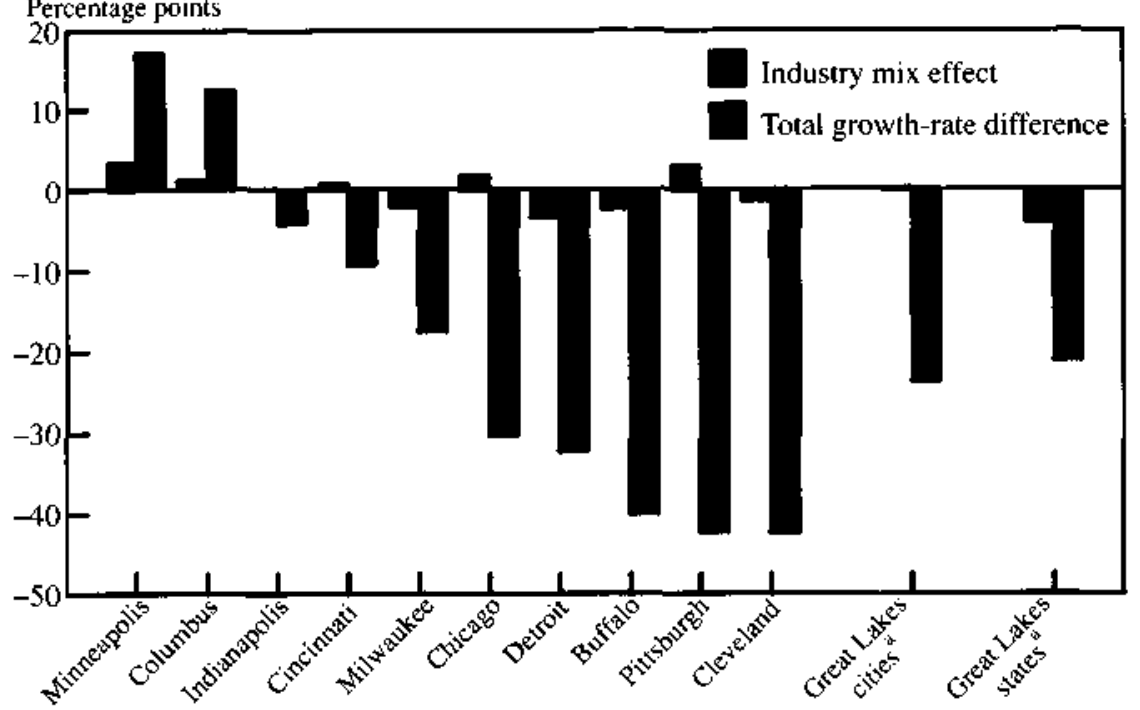

FIGURE 2 MANUFACTURING LQS, 1969 AND 1989

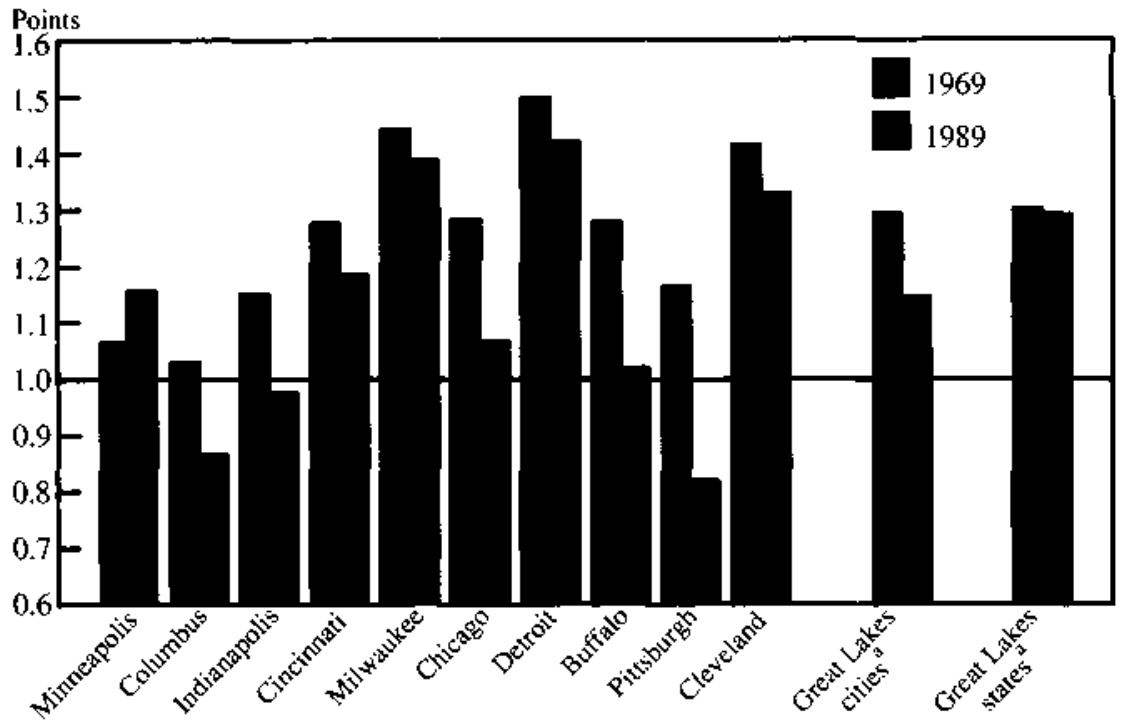

a. Means.

SOURCE: U.S. Deparment of Commerce. Bureau of Economic Analysis, Regional Economic Information Service Data Base.

two others (Chicago and Buffalo) were not far behind. Furthermore, Milwaukee, Detroit, and Cleveland began the period with manufacturing shares more than 40 percent above the national average. Two decades of change have brought these manufacturing giants more in line with the rest of the country, although they still maintain their strong specialization.

One area's high concentration in a particular industry implies that other areas have LQs below one. Thus, manufacturing's dwindling concentration in the Midwest cities examined here raises a critical question: Was the decline counter- balanced by a growing number of factory jobs in other regions or in the nonmetropolitan and smaller urban areas within the Midwest itself?

The bars on the far right of figure 2 provide the answer. Between 1969 and 1989, the manufacturing $L Q$ fell only 0.012 for the Great Lakes states, a neg]igible drop. In contrast, the region's 10 largest MSAs experienced losses averaging more than 12 times as much $(0.149)$. This means that, relative to the rest of the nation, virtually all of the shrinkage in manufackuring's share of jobs in these cities was offset by increases in factory jobs in smaller municipalities or rural areas of the Midwest.

Of course, the new jobs are probably not the same as those once found in the major metropolises. They may be in different firms or they may reflect marked reorganizations of production. However, in terms of overall flows. it is obvious that factory jobs in the largest Midwest cities are being replaced by jobs in the surrounding areas. Of the cities examined here, only Minneapolis increased its manufacturing $L Q$, while 36 of the 80 smaller municipalities in the region showed relative gains.

This same pattern can also be detected throughout the rest of the country, albeit in a more muted form. Across all U.S. MSAs. the manufacturing $L Q$ fell from 1.03 in 1969 to 0.96 in 1989 . signaling a general transfer of factory jobs from urban to rural locations. In addition, many smaller cities posted gains relative to the nation's major metropolitan centers.

This evidence calls into question the common perception that the Midwest cities lost so many manufacturing jobs in the last two decades because the region was at a competitive disadvantage relative to other areas of the country. Instead, it appears that greater geographic dispersion of manufacturing within the region played a more important role, as factory jobs became more evenly spread among large urban, small urban, and nural areas.

Several factors may enter into a manufacturer's decision to locate outside large-city boundaries, including the recent decline in transportation and communication costs, shrinking plant sizes, greater awareness of the costs of environmental contamination. and union avoidance. Service providers, on the other hand, enjoy the urban advantages of first-class office space, easy access to information transfer systems, and a pool of seasoned workers from other service firms and local universities. 
- The Rust Belt Cities as Service Centers

Does this loss of factory jobs mean that the Midwest's principal cities are losing their raison d' $\hat{t} t r e$ ? The answer is no, because a major reason businesses once chose to set up shop in thriving metropolises was easy access to needed services. Now, although other considerations may dictate that factories move to less populous areas, the big cities are not losing service jobs- they are gaining them. This suggests that manufacturers and other firms are continuing to patronize large-city service providers even from out of town.

Figure 3 shows that the share of serviceindustry employment rose in all 10 MSAs over the $1969-89$ period. While absolute employment growth rates in the service trades lagged the U.S. average in most cases (see table I). the mean LQ increase from 0.99 to 1.09 indicates that services actually grew more rapidly relative to total employment in these metropolises than in the nation as a whole. Although only four cities specialized in services in 1969. eight did so by 1989 , and the remaining two were headed in that direction.

Part of the swell in service jobs may well represent "catch-up" growth. The Midwest states' relative deficit of service employment has declined dramatically, due largely to the industry's strength in the region's urban centers. In particular, the Midwest's total urban LQ (large plus small cities) for services rose from 0.90 to 0.97 in 1989, while the figure for all U.S. MSAs picked up only slightly (from 1.04 to 1.05 ). Regionally, service jobs have been added most rapidly in the largest cities, where the average share of such positions now exceeds the national MSA level. Thus, while neither the region as a whole nor its smaller municipalities are now net exporters of services, most of its biggest cities are. This means that much of the increase in service employment can probably be traced to the rise of these cities as service centers for their surrounding communities.

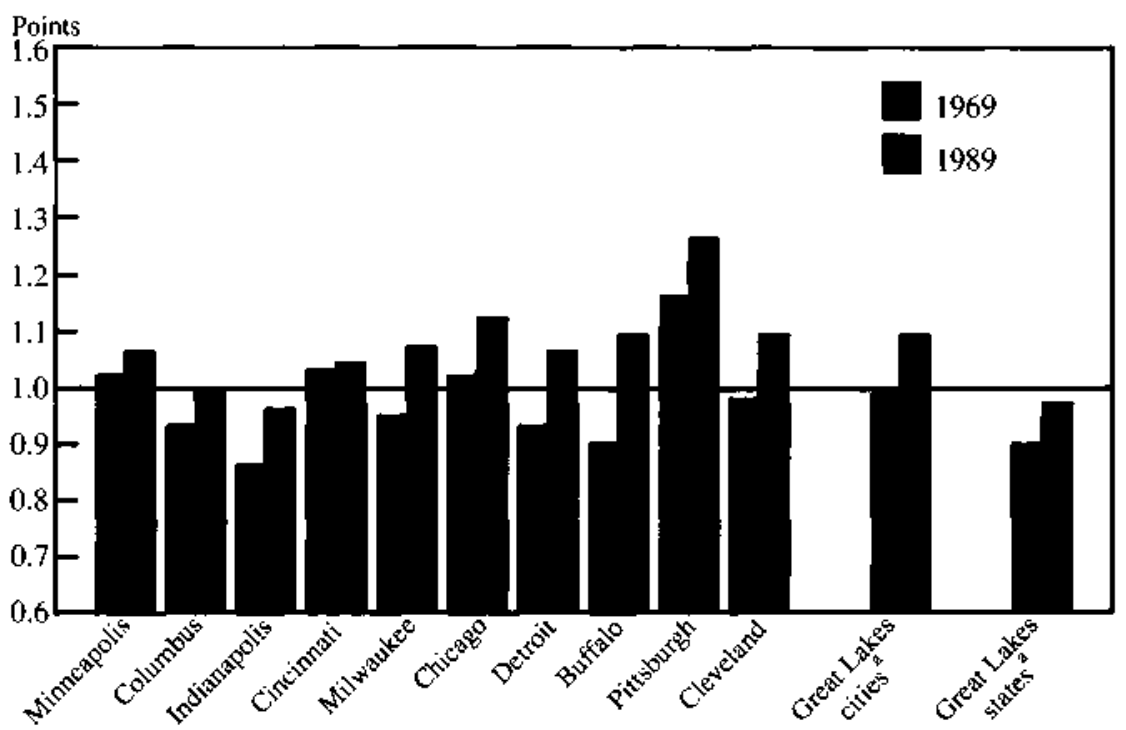

a. Means.

SOURCE: U.S. Department of Conmerce, Bureau of Economic Analysis, Regional Economic Information Service Data Base.

Although the Midwest MSAs lost proportionally more factory jobs than did the nation, they also replaced them more rapidly with service jobs (again in proportional terms). This pattem runs counter to the common assumption that because service-sector growth is based solely on local demand, it can pick up only as a by-product of growth in export-oriented manufacturing. Based on the experience of the Midwest and other regions, it now appears that services are increasingly exportable. ${ }^{6}$ This makes sense if one considers the technological advances witnessed since the late 1960 s. For instance, the introduction of fax machines and electronic mail, coupled with the drop in air travel costs, has made it more feasible and cheaper for an architectural fum in Pittsburgh to design a building for a client in Seattle.

For some Midwest cities, like Detroit, service specialization has added to a continuing manufacturing concentration. For others, like Pittsburgh, service positions seem to be replacing factory jobs. The bottom line is that as producers of services, the cities along the Great Lakes may never regain the national dominance they once enjoyed as manufacturing kingpins: The 1989 service LQs still lag the 1969 manufacturing LQs for every locale except Pittsburgh.
Nonetheless, all 10 of these cities are stepping up their emphasis on providing services to customers outside their borders.

\section{Growth Potential in a Service-Based Economy} In light of the service industry's position as an important employer in the Great Lakes cities of the nineties, the potential for growth in this sector is a crucial issue. Can services growth spin off into other areas of the economy the way manufacturing growth has?

The regional multipliers for Ohio, which show the economic ramifications of rising expenditures or employment in a particular industry, reveal that bringing in a business service provider generating $\$ I$ million in annual revenue creates 41 more jobs, while bringing in a tire manufacturer that does the same amount of business creates only 23 more. ${ }^{7}$ The service provider also augments earning power to a greater extent than does the manufacturer. For each additional dollar earned by the service firm, household eamings rise by 89 cents, versus 54 cents for the manufacturer. A comparison of aggregated services and manufacturing exhibits the same pattem as shown in this simple example. 
The fact that services are more labor intensive (and thus add more jobs directly) is not the only reason that the growth of service-industry output creates more jobs per dollar. Breaking down the effect of output increases on job growth shows that the aforementioned business service provider hires 22 new employees and causes firms in other industries to take on 18 new hires. The tire manufacturer, by contrast, adds only nine new employees and causes other firms to hire $14 .^{8}$ Although one job in services induces less hiring in other industries, raising services pro. disction by a certain dollar amount yields more new positions in other industries than does the same rise in manufacturing sales.

From an economic development perspecive, it should also be noted that, on average, individual service establishments employ fewer people and produce fewer dollars of output than do manufacturing concerns. This means that an area has to attract more service providers than manufacturers to achieve the same spin-off effects for a $\$ 1$ million increase in output. The decision regarding which type of firm to pursue depends on the cost of wooing the $\$ 1$ million service output versus the $\$ 1$ million of manufactured products. For example, the extra costs of attracting four $\$ 250,000$ service providers to a city versus a single $\$ 1$ million manufacturer could well wipe out the benefits of the formers' more rapid growth potential.
Service vs. Manufacturing Wages What does this transformation mean for workers in the Great Lakes MSAs? Much has been made of the fact that average wages are lower in the service sector than in the manufacturing sector. Still, the news is not entirely bleak. Different, and more general, skills will be demanded of the Midwest's urban work force, so education and retraining will be a top priority. Service-sector positions tend to require higher entrylevel skills than do manufacturing jobs, and they also reward people more lucratively for advanced education. ${ }^{9}$ Those holding service positions, from repair technicians to accountants, rely on fundamental English and math skills for such basic tasks as reading manuals and setting up balance sheets. Without access to retraining. workers with a high school education or less are especially likely to fall through the cracks as the nation shifts from a manufacturing- to a service-based economy.

Controlling for demographic differences (such as age, race, and sex), servicesector workers eam 12 to 16 percent less per hour than do manufacturing workers, and this difference remains essentially constant as workers grow older. ${ }^{10}$ Since an additional year of education is currently estimated to boost eamings by about 7 percent, a service worker needs nearly two more years of schooling to earn what he or she would have made in a factory job. Although this may be a daunting prospect for older workers, it is new entrants who are filling most of the service openings, and they seem to be enrotling in (and returning to) college in record proportions. ${ }^{\text {] }}$

\section{Conclusion}

During the $1970 \mathrm{~s}$ and $1980 \mathrm{~s}$, controlling for other regions ' faster overall growth and the general loss of U.S. manufacturing jobs, the Great Lakes region did not suffer a reduction in its concentration of factory positions. However, the area's 10 largest cities saw a huge drop in their shares, as urban losses were counterbalanced by payroll increases in tactories located in smaller MSAs and nural counties throughout the region. Meanwhile, despite their shrinking manufacturing base. all 10 cities raised their share of service jobs substantially, mostly to levels well above the national average.

These simple facts, when combined with reports of recent improvements in U.S. business management strategies. suggest that the Midwest's principal cities are becoming service centers for manufacturing establishments and other customers located outside their boundaries. Thus, the health of these cities" economies over the coming decades will depend more and more on the vitality of their service industries. Local governments, mindful of manufacturing's traditional importance, have generally devised their economic plans and educational policies with an eye toward the industry's continued health. In light of the results presented here. it appears that this strategy should be reconsidered and perhaps modified to reflect the growing needs of service providers. 


\section{Footnotes}

1. The Great Lakes states are Illinois, Indiand. Michigan, Minnesota, Ohio, and Wisconsin

2. The narrow definition of service industries used here includes firms providing educational, health, business, and personal services

3. Industrial mix is the deviation from the U.S. growth rale attributable to a city's unique industrial structure. We consider eight categories of employment to determine the initial mix: construction; manufacturing: transportation, communication, and public utilities; wholesale and retail trade; services finance, insurance, and real estate: and govermment. The levet of aggregation is kept quite broad in order to capture just the differential influence of manufacturing and services. For a further discussion of industrial mix and market-share effects, see Gerald $\mathrm{H}$. Anderson, "Is the Rust Belt's Revival Real?" Federal Reserve Bank of Cleveland. E' $(0$ nomic Commentary, March 1, 1992

4. The manufacturing and service sectors together account for approximately 40 percent of total U.S. employment.

5. For a review of these trends in the Midwest, see William A. Testa. "Trends and Prospects for Rural Manufacturing." Federal Reserve Bank of Chicago, Economic Per. spectives, vol. 17, no. 2(March/April 1993), pp. 27-36.

6. For an in-depth look at this issue, see Erica L. Groshen. "Can Services Be a Source of Export-Led Growth? Evidence from the Fourth District," Federal Reserve Bank of Cleveland, Economic Revien', Quarter 3 1987, pp. 2-15.
7. These 1989 regional multipliers were taken from Regional Multipliers: A User Handbosk for the Regional Input-Output Modeling System (RIMS II). U.S. Departnent of Commerce, Bureau of Economic Analysis, May 1992

8. The number of jobs created by increases in output within a given industry is calculated by dividing the final-demand employment multiplier by the direct-effect employment multiplier.

9. See John Swinton. "Service Sector Wages: The Importance of Education," Federal Reserve Bank of Cleveland. Economic Commentary, December 15. 1988.

10. See Randall W. Eberts and Erica L Groshen, "Do the Wages of Manufacturing and Service Workers Grow at the Same Rate over Their Careers?" Federal Reserve Bank of Cleveland, Economic Revien: Quarter 4 1988, pp. 2-10.

11. For a discussion of the rising value of education, see Erica L. Groshen and Colin Drozdowski, "The Rising Value of Education: Market Forces at Work." Federal Reserve Bank of Cleveland. Ecomomic Commentary, August 15, 1992. For a look at how the value of education has increased the most in large ciries. see Patricia Beeson and Erica L. Groshen. "Components of the City-Size Wage Differential," Federal Reserve Bank of Cleveland, $E_{t} O$. nomic Revien: vol. 27, no. 4 (Quarter 4 1991). pp. 1-24.
Erica L. Groshen is an economic advisor and Laura Robertson was a 1992 summer intern at the Federal Reserve Bank of Cleveland. The authors thank Parricia Beeson, EJ Stevens, and Randall Eberts for heloful comments and suggestions.

The view's stated herein are those of the authors and not necessarily those of the Federal Resene Bank of Cleveland or of the Board of Governors of the Federal Reserve System

Federal Reserve Bank of Cleveland

Research Department

P.O. Box 6387

Cleveland, OH 44101

Address Correction Requested: Please send corrected mailing label to the above address. 